\title{
Hodgkin's disease following infectious mononucleosis
}

\author{
T. J. RoBINSON \\ M.D., M.R.C.P.
}

\author{
Banbridge Hospital, Banbridge, County Down, Northern Ireland
}

\begin{abstract}
Summary
A case of Hodgkin's disease occurring 4 years after the onset of infectious mononucleosis is described. Persistence of symptoms, physical signs and Paul Bunnell test are noted and the possible association of persistent infectious mononucleosis and development of Hodgkin's disease is discussed.
\end{abstract}

\section{Introduction}

THE association of infectious mononucleosis and malignant lymphoproliferative disorders has been the subject of several case reports, and a recent retrospective study has shown a greater than expected incidence of Hodgkin's disease in males who had had a positive Paul Bunnell titre (Rosdahl, Larsen and Clemmeson, 1974).

\section{Case report}

A 23-year-old male patient was admitted with 2 weeks' history of a fever and sore throat 'with membranous exudate' for which he had been treated with ampicillin. There was a generalized maculopapular rash consistent with an ampicillin sensitivity eruption, generalized lymphadenopathy, splenomegaly and slight icterus. Tonsils were enlarged but 'without exudate' and there were petechiae on the palate.

Haemoglobin was $91 \%$ and the white cell count $16,200 / \mathrm{mm}^{3}$ with $20 \%$ polymorphs, $8 \%$ monocytes and $72 \%$ lymphocytes, many of which were atypical. The Paul Bunnell was positive at $1 / 320$ with the absorption tests those of infectious mononucleosis. He became afebrile and symptom free within a few days of admission and was discharged home.

He was seen 9 months later complaining of fast beating of the heart, sweating on moderate activity and weakness although still able to play football. Examination showed glandular enlargement in the axillae, splenomegaly two finger breadths below the costal margin and the liver edge was palpable.

Haemoglobin was $107 \%$, white cell count 8,000 / $\mathrm{mm}^{3}$ with no abnormality in differential white cell count and atypical lymphocytes were absent. Paul Bunnell was still positive at $1 / 320$.

At review 6 months later he still complained of episodes of tiredness and pyrexia. Splenomegaly was still present and he had firm, palpable axillary nodes. Paul Bunnell was negative. Haemoglobin and white cell counts were normal but alkaline phosphatase was slightly raised at $20 \mathrm{KA} \mathrm{u} / 100 \mathrm{ml}$.

Subsequent follow-up was arranged but the patient failed to attend. Four years after his initial illness and 30 months after his last attendance he was readmitted as an emergency with a 9 months' history of night sweating which had become much worse in the last 2 weeks. He had noticed a swelling in his neck and following a course of ampicillin had developed a generalized rash. He was pyrexial and had discrete lymph nodes in the left side of his neck in the posterior triangle, and lymph nodes were palpably enlarged in both axillae and in both inguinal regions. The spleen was just palpable.

Haemoglobin was $89 \%$ with a white cell count of 7,000 ; polymorphs, $64 \%$; lymphocytes, $27 \%$; monocytes, $7 \%$; eosinophils, $4 \%$; no atypical lymphocytes were seen; Paul Bunnell was just positive to a titre of $1 / 8$.

A provisional diagnosis of recticulosis was made and cervical lymph nodes were biopsied. The pathological report was as follows: 'The architecture of this lymph node is lost. Around the periphery there is proliferation of lymphocytic and histocytic cells with considerable dominance of lymphocytes, but towards the centre and involving the greater part of the lymph node the cellular proliferation is more mixed with eosinophils and numerous atypical reticulum cells and Reed-Sternberg cells. There is little necrosis. This pattern corresponds to that of the mixed cellularity variant and is one of the less favourable types of Hodgkin's disease. DiagnosisHodgkin's disease (mixed cellularity).'

He was subsequently transferred to another Unit and included in the National Lymphoma investigation.

Laparotomy revealed para-aortic glands with splenic involvement. He was started on combination cyclical therapy with $9 \mathrm{mg}$ mustine i.v. on the first and eighth days and $2 \mathrm{mg}$ vincristine i.v. on the same days, $50 \mathrm{mg}$ natulan t.i.d. for 10 days and $40 \mathrm{mg}$ prednisone daily for 14 days. 
A good clinical remission has been obtained and he continues on cyclical therapy at 6 week intervals.

\section{Discussion}

Circumstantial evidence linking acute lymphoblastic leukaemia, Hodgkin's disease and Burkitt's lymphoma with acute infectious mononucleosis is accumulating and it is tempting to speculate that all four conditions are different responses to one stimulus, probably the Epstein-Barr virus. Levine et al. (1972) reported three cases of acute lymphocytic leukaemia preceded by infectious mononucleosis in males aged 20,12 and 16 years. In their first case acute lymphocytic leukaemia was diagnosed 15 months after the initial infection and the patient presented as a 'recurrent' infectious mononucleosis and the other two cases developed acute lymphocytic leukaemia concurrently with infectious mononucleosis. The case of Hodgkin's disease described by English (1970) occurred 7 months after infectious mononucleosis and the slide test was negative at the time of the diagnosis of Hodgkin's disease.

The place of the Epstein-Barr virus as the causative agent in infectious mononucleosis is becoming established (Pereira et al., 1972; Henle, Henle and Diehl, 1968; Niederman et al., 1968) as is its place in Burkett's lymphoma (Henle et al., 1968), and Burkett's lymphoma has followed infectious mononucleosis (Cohen et al., 1970). In cases of acute lymophocytic leukaemia described by Levine et al. (1972) and the case of Hodgkin's described by English (1970), Epstein-Barr antibodies were demonstrated, and these antibodies have been shown to be distinct from the heterophil antibody measured in the Paul Bunnell reaction.

In the retrospective study reported by Rosdahl $e t$ al. (1974) it was shown that a follow-up of patients with positive Paul Bunnell produced an increased incidence in males of Hodgkin's disease occurring at an interval of greater than 12 months. Infectious mononucleosis is classically a disease of young people aged 15 to 20 years and females tend to be affected younger than males, so maybe the risk of developing Hodgkin's disease increases with the age of onset of infectious mononucleosis.
In this case of Hodgkin's disease several unusua features were present which may be of significance $\frac{3}{8}$ Although convalescence is often prolonged in in fectious mononucleosis, the Paul Bunnell titre andsplenomegaly does not usually persist as long as here described, and perhaps a chronic type of infectious mononucleosis may have occurred which may have् provoked malignant transformation.

Ampicillin allergy occurring at the time of then diagnosis of Hodgkin's disease must also be unusuaf as there is usually diminished sensitivity in Hodgkin's $s$ disease (Smithers, 1967).

It is difficult to know at what stage this patient's disease changed from chronic or persistent monow nucleosis to Hodgkin's disease and it may be that cases of infectious mononucleosis which behave in an atypical manner should be assessed critically in caser malignant change is occurring.

\section{References}

Cohen, M.H., Hirshaut, Y., Stevens, D., Hill, E.W.음 Davis, J.H. \& Carbone, P.P. (1970) Infectious mono=nucleosis followed by Burkitt's lymphoma. Annals of Internal Medicine, 73, 591.

ENGLISH, J.M. (1970) Infectious mononucleosis followed by Hodgkin's disease. Lancet, i, 948 .

Henle, G., Henle, W. \& Diehl, V. (1968) Relation융 Burkitt's tumour-associated herpes-type virus to infecti@us: mononucleosis. Proceedings of the National Academy Sciences of the United States of America, 59, 94.

Levine, P.H., Stevens, D.A., Coccia, P.F., Dabich, L. $\& \overline{\bar{O}}$ RolAND, A. (1972) Infectious mononucleosis prior to acute leukaemia: a possible role for the Epstein-Barr virus.\$ Cancer, N. York, Philadelphia, etc., 30, 875.

Niederman, J.C., McCollum, R.W., Henle, G. \& Henle W. (1968) Infectious mononucleosis-clinical manifesta 3 tion in relation to Epstein-Barr virus antibodies. Journal of the American Medical Association, 203, 205.

Pereira, M., Field, A., Blake, J., Rodgers, F.G., Bailey L.A. \& Davies (1972) Evidence for oral excision of Epstein-Barr virus in infectious mononucleosis. Lancet, 710.

Rosdahl, N., larsen, S.O. \& Clemmeson, J. (1974) Hodg kin's disease in patients with previous infectious mono nucleosis: 30 years' experience. British Medical Journal, 2, 253.

Smithers, D.W. (1967) Hodgkin's disease II. British Medica Journal, 1, 337. 